\title{
Ensaio
}

\section{A degeneração e a repetição da origem: Análise da vivência mitológica da história nas sociedades melanésias}

Robson Rocha de Souza Júnior*

\begin{abstract}
Resumo
0 principal interesse desse trabalho é esmiuçar a questão acerca da formação de trajetórias históricas em sociedades arcaicas com base na argumentação de neo-institucionalistas históricos (sobretudo Paul Pierson), tomando como referência de análise as especificidades da experiência histórica numa sociedade arcaica particular: os melanésios descritos por Malinowski no início do Século XX. Ao tratarmos de uma sociedade arcaica como a melanésia, o mais importante é analisar o modo como esses nativos atribuem sentido mitológico à sua realidade histórica, pois essa é, sem dúvida, uma das principais características da experiência histórica em sociedades arcaicas.
\end{abstract}

\section{Palavras-chave}

Melanésia. História. Mitologia. Dependência de trajetória.

\section{Abstract}

This paper focuses on the issue of the formation of historical trajectories in archaic societies. It is based on the arguments of neo-institutionalistic historians, such as Paul Pierson. It takes as its object the particularities of historical experience in one specific archaic society: the Melanesian people described by Malinowski in the beginning of the 20 th century. The analysis is devoted to the way these natives attribute mythological meanings to their historical reality as one of the main features of historical experience in archaic societies.

\section{Keywords}

Melanesia. History. Mythology. Trajectory dependency.

\footnotetext{
* Robson Rocha de Souza Júnior é Mestre em Ciências Sociais pela Universidade Federal de Juiz de Fora (UFJF) e Doutorando em Sociologia junto ao Programa de Pós-Graduação em Sociologia da Universidade Federal do Rio Grande do Sul (PPGS / UFRGS). E-mail: robson.rocha.jr@hotmail.com.
} 


\section{Introdução}

O que faz com que acontecimentos descontínuos se unam no curso histórico para formar uma série coerente em que cada acontecimento recebe sentido do seu antecessor e confere sentido ao acontecimento que lhe sucede? Segundo nos parece, os neoinstitucionalistas históricos (especialmente Paul Pierson) nos dão indicações importantes acerca dessa questão. A marca principal de sua argumentação pode ser definida como uma tentativa de considerar, ao mesmo tempo e de forma intercalada, a mudança e a estabilidade na análise de processos históricos com base num conceito de "causa histórica" que se refere a processos que geram dependência de trajetória e que se mantêm, porque estão baseados em mecanismos socioculturais específicos que permitem a formação de um feedback positive, baseada num arranjo institucional constituído que pressiona os atores a se ajustarem às suas regras estabelecidas. Mas será que essa mesma formulação tem validade para experiências históricas não ocidentais? Ou, dito de outro modo, como se formam as trajetórias históricas em sociedades tradicionais?

O interesse deste trabalho é esmiuçar essa questão com base na análise das especificidades da experiência histórica numa sociedade arcaica específica: os melanésios descritos por Malinowski no início do século XX. Para analisarmos a diferença relativa entre o curso histórico ocidental e o não ocidental, será fundamental nos valermos dos argumentos de Paul Pierson acerca das trajetórias históricas, pois, a partir dos pontos nevrálgicos de sua reflexão, ser-nos-á possível definir o que distingue e o que aproxima o modelo ocidental desse modo específico de dar significado à realidade histórica, o modo melanésio (1).

Primeiramente, deve-se destacar que, ao invés de conceberem o curso histórico como uma progressão de acontecimentos sucessivos, esses nativos o concebem como uma trajetória de degeneração que não é progressiva, mas sim abrupta. Para os melanésios, a perda desse elo com o passado mítico representou a degeneração dos homens na atualidade histórica, o que não pode ser refeito. Há, portanto, para esses nativos, uma espécie de feedback negative, que marca seu curso temporal, mas que não forma uma série progressiva de degeneração, e sim abrupta (2). Não obstante, além de uma separação abrupta entre a época mitológica e a época histórica, há também a noção de que esse passado mítico não fora perdido por completo e pode, por assim dizer, ser repetido por meio da magia. Sendo assim, a história para esses nativos não seria apenas um processo abrupto e negativo, mas 
também parcialmente repetitivo, o que nos permite caracterizar o modo como concebem o curso histórico como um feedback repetitive. (3)

\section{As trajetórias históricas}

Voltamos então à questão: o que permite o estabelecimento da unidade entre acontecimentos históricos que resulta naquela totalidade que caracteriza os períodos históricos? É o que aborda Paul Pierson em Politics in time (PIERSON, 2004). O conceito central de sua argumentação, como já comentado alhures, é um conceito específico de "causa histórica", a partir do qual ele intenta analisar variados complexos de acontecimentos históricos que articulam estabilidade e mudança, tomando-as como dois aspectos de um mesmo processo. Mas que tipo de causa histórica é essa?

O traço característico dessa causa histórica, ou do modo como ela opera na conjunção dos acontecimentos, é o fato de ela criar uma dependência de trajetória (path dependence), o que se refere ao autorreforço (self-reinforcing) ou feedback positive, que caracteriza os processos históricos. Logo, os períodos históricos se formam ao constituírem trajetórias que têm um aspecto causal que impele os acontecimentos posteriores a se enquadrarem à sua lógica. Essa forma específica de conceber o curso histórico aposta, portanto, na ideia de que determinados cursos de ação - sobretudo aqueles que têm peso histórico - uma vez que já estejam consolidados, tornam-se virtualmente impossíveis de serem revertidos, justamente pela determinação causal da trajetória. Ocorre que, quando uma trajetória é escolhida e adotada, os custos de revertê-la são muito altos, e os atores, ao invés de insistirem em sua mudança, tendem, na verdade, a seguir seus ditames e se adaptar a ela:

\footnotetext{
“Na presença de positive feedback a probabilidade de passos seguintes ao longo do mesmo percurso aumentam com cada movimento nessa trajetória. Isso porque os benefícios relativos da atividade corrente comparados com as opções outrora disponíveis são incrementadas com o passar do tempo. Posto de forma distinta, os custos da mudança para alguma alternativa anteriormente disponível aumentam".
}

(PIERSON, 2004, p. 21)

Por isso, a cada passo em direção à consolidação de uma trajetória, mais difícil se torna reverter seu curso, o que significa que a história poderia ser definida como um processo irreversível com uma série de encruzilhadas. 
Essa definição salienta as possibilidades de desvio e mudança dessa trajetória, proporcionadas pelas encruzilhadas; mas não deixa de acentuar sua peculiar resiliência à mudança, em virtude de sua irreversibilidade. Isso significa que toda sequência de acontecimentos históricos é marcada por uma dinâmica de autorreforço que apresenta uma grande instabilidade no início, condição que, com o passar do tempo, vai sendo superada até que se alcance uma estabilidade considerável, sobretudo após ter se consolidado numa trajetória.

Posto isso, como as trajetórias implicam determinado tipo de causalidade, o importante é desvelar os mecanismos mobilizados no estabelecimento desse autorreforço, pois esses são os fatores que permitem a formação e a manutenção das trajetórias históricas. É por isso que, para Pierson, os processos com feedback positive que geram dependência de trajetória resultam necessariamente da institucionalização de arranjos sociais, e são justamente esses arranjos que garantem estabilidade à trajetória. Posto isso, pode-se dizer que os diversos padrões de conexão temporal entre eventos (trajetórias históricas) estão baseados em mecanismos socioculturais específicos que permitem a formação de um feedback positive, de uma dependência de trajetória.

“Identificar processos de auto-reforço nos ajuda a compreender
porque práticas organizacionais e institucionais são, com
frequência, extremamente persistentes [...] Afirmar que o âmbito
social pode estar permanentemente cristalizado [frozen] é
fortemente crível, mas essa não é a alegação. A mudança continua,
apesar de ser uma mudança limitada - até que algo corroa ou
inunde os mecanismos de reprodução que geram a continuidade".
(PIERSON, 2004, p. 52)

O processo de institucionalização se refere a uma estabilização de equilíbrio interativo entre múltiplos atores, o que é possível apenas após um longo processo de amadurecimento histórico. Toda instituição está sustentada numa série organizada e coesa de normas, valores, e concepções - também institucionalizadas de algum modo - que orientam a ação dos atores e impedem mudanças bruscas. Uma trajetória é irreversível em virtude do poder exercido por essas regras institucionalizadas sobre a ação - sobretudo porque ela não apenas indica aquilo que deve ser feito, ou seja, que uma regra existe e que ele deve ser seguida; mas também que outra possibilidade qualquer sequer é possível, pois as escolhas feitas no passado 
são relativamente irreversíveis e limitam o âmbito de escolha das ações futuras:

\begin{abstract}
"Argumentos baseados no positive feedback e no sequenciamento apresentam um alicerce fundamental para alegações sobre por que e como a historia importa. Em todos os estudos sobre sequências como dependência de trajetória, algumas sequências históricas particulares são importantes porque processos iniciais geram formas organizacionais e arranjos institucionais específicos, duradouros e altamente determinantes [highly consequential] que alteram as implicações de eventos ou processos posteriores".

(PIERSON, 2004, p. 71)
\end{abstract}

Uma vez instituído, o arranjo institucional pressiona os atores a se ajustarem às suas regras estabelecidas, ao mesmo tempo em que facilita a formação de instituições que alimentam e complementam sua articulação basilar. Logo, à medida que um arranjo institucional se desenvolve, tornase mais resistente à mudança, o que tende a promover um equilíbrio institucional profundo capaz de durar por um longo período de tempo. Isso porque em contextos de complexa interdependência social cada nova instituição que pode vir a surgir tende a se adaptar às instituições já consolidadas e ao todo articulado que elas formam. Mas como é possível que esse conjunto articulado de regras impeça a mudança?

Essa resiliência é possível em virtude do condicionamento exercido pelo arranjo institucional sobre a ação. Logo, é a partir da imposição institucional sobre a ação social que o curso histórico se estabiliza numa trajetória. Por isso, seu comportamento é, em grande medida, apenas um reflexo desse equilíbrio institucional, o que significa que os atores não têm qualquer incentivo para alterar seu comportamento já há muito adequado. As pessoas estão desde sempre adaptadas aos padrões institucionais, então elas tendem a estabelecer, inevitavelmente, uma série de compromissos baseados na expectativa de que essas regras institucionalizadas continuem a vigorar. E como essas expectativas projetadas são decisivas para cada indivíduo em particular, é muito provável que ele se oponha a qualquer possibilidade de mudança: seja porque ele já domina certas habilidades que são indispensáveis para a operação de atividades importantes em contextos institucionais específicos, seja por causa de seu relacionamento estabilizado com outros atores influentes nos arranjos institucionais específicos, em função, sobretudo, de sua posição social em cada contexto. Por ambos 
os motivos, os atores vinculados a determinado arranjo institucional não têm motivos coerentes para romper com ele, o que os leva a manter sua expectativa de que a coordenação que constitui tal arranjo se mantenha. Como sustenta Paul Pierson, isso ocorre porque "Contextos sociais particulares constrangem e habilitam os atores políticos e, na verdade, podem moldar muito a compreensão desses atores acerca de quem eles são e o que eles querem realizar." (PIERSON, 2004, p.169).

Por isso, como sustentam Hall e Tylor, as organizações sociais podem ser definidas como "um complexo de instituições capaz de estruturar a natureza e os resultados dos conflitos entre grupos" (HALL; TYLOR, 2003, p. 195), ou seja, capaz de "estruturar as relações sociais de modo a engendrar situações políticas e econômicas próprias" (HALL; TYLOR, 2003, p.195). Toda organização social é, portanto, extremamente complexa e articula uma gama de instituições concorrentes. Ela é caracterizada por uma vinculação interpessoal preexistente que constitui sua configuração própria específica e que pode ser definida como uma rede de funções interdependentes pelas quais as pessoas estão ligadas entre si de maneira decisiva.

Já os padrões culturais apresentam outra característica. Como nos demonstra Geertz, trata-se de um sistema simbólico que modela o comportamento público (GEERTZ, 1989, p. 68) ao articular o estilo de vida de um povo (seu ethos) à sua visão de mundo (GEERTZ, 1989, p. 66-67). Todo padrão cultural está alicerçado, então, numa institucionalização do sentido e, por consequência, numa institucionalização da ação. Essa dupla institucionalização permite a formação de comportamentos rotineiros. $\mathrm{O}$ ator tende a seguir essas rotinas definidas pela visão de mundo específica que dá sentido e valor à realidade que ele vive e compartilha com outros atores, o que deverá se consolidar num estilo de vida, num éthos específico que reduz a ambiguidade da ação. Isso quer dizer que, ao agir, o ator não tem em mente prioritariamente os ganhos que sua ação pode promover, mas sim a sua conformidade às regras e valores estabelecidos. Sua ação segue uma rotina específica definida para cada situação, na medida em que a rotina se refere às "regras de procedimento que especificam um processo que deve ser seguido em determinadas circunstâncias." (MARCH; OLSEN, 1989, p. 22). Ele tem, em suma, que identificar a situação em que está envolvido, que posição ele ocupa em tal situação e quais são as ações apropriadas para ele nessa situação.

Todo curso histórico alimenta, então, a consolidação de uma matriz institucional específica ao impor regras específicas aos agentes, estes 
últimos, ao se adequarem a esse arranjo complexo, tenderão a mantê-lo muito mais do que a alterá-lo. Esse arranjo institucional reforça a trajetória histórica que o constituiu, contribuindo para sua manutenção ao longo do tempo. Agora podemos avaliar o caso não ocidental.

\section{A degeneração do curso histórico e a repetição da origem através da magia}

A questão acerca da diferença relativa entre a experiência histórica ocidental e a não ocidental parte de duas premissas: por um lado, a de que há uma diferença fundamental entre o modo ocidental de vivenciar a história e o modo como essas sociedades arcaicas o vivenciam, embora essa diferença não possa, por outro lado, ser exagerada. Para analisarmos essa diferença relativa, será fundamental nos valermos da explanação de Malinowski referente à experiência histórica específica dos melanésios. A análise de Malinowski será determinante, pois tem o mérito de levar a reflexão ao seu ponto central.

Malinowski trata da mitologia melanésia em Os Argonautas do Pacífico Ocidental (1976) em dois importantes capítulos: no Capítulo XII, no qual, além de uma reflexão teórica sobre a relação entre mito e história, também é considerada a mitologia associada ao Kula; e no Capítulo XVII, que complementa essa discussão, mas agora com o foco no importante papel da magia. Apesar de localizadas em partes distintas de seu livro, ambas as passagens estabelecem a mesma digressão. Vejamos como Malinowski trata do assunto.

Antes de tudo, Malinowski se questiona: o que é mito para os nativos? Qual é a sua concepção e sua definição de mito? Eles são demarcados da realidade? Se sim, como isso é feito? Para responder a essas indagações, Malinowski enumera, primeiramente, as cinco categorias de folclore reconhecidas pelos nativos: (1) libogwo, que representa o "falar antigo", a tradição; (2) kukwanebo, que se refere aos contos de fada não verdadeiros destinados à diversão; (3) wosi, que são as diversas canções que possuem; (4) yinavina, que são cançonetas e folguedos; e, enfim, (5) megwa ou yopa, que são as fórmulas mágicas. Segundo Malinowski, contudo, o que de fato interessa para tratar daquelas questões é o libogwo, o "falar antigo", a tradição. O libogwo, por sua vez, pode ser subdividido em duas categorias: os contos históricos, referentes aos feitos dos grandes chefes e às histórias 
de naufrágio (a); e o que os nativos chamam de lili'u, que são justamente os mitos, narrativas nas quais os nativos acreditam, respeitam e que, por isso, têm grande influência sobre o seu comportamento (b).

O lili'u se refere a um tempo extremamente remoto. Mas é importante salientar que a história não é, para esses nativos, um desenrolar em tempos sucessivos. Na verdade, eles distinguem apenas os acontecimentos que aconteceram no âmbito de sua própria memória e de seus pais e, além dessa demarcação, todos os acontecimentos se aglomeram num único plano. O passado seria, portanto, um vasto acervo de acontecimentos não sucessivos. Por isso, apesar de haver uma distinção entre mito e história, essa diferença não é formulada através das mesmas demarcações temporais que os ocidentais reconhecem. Ocorre que, para eles, a história não se desenrola numa evolução constituída de uma série de mudanças sucessivas e progressivas, já que a terra e a humanidade foram, são e serão sempre as mesmas: eternamente jovens. Não por acaso, tanto na realidade como nos mitos, as pessoas possuem os mesmos interesses e preocupações:

"As personagens míticas das lendas nativas, como veremos em
breve, moram no mesmo tipo de casas, comem o mesmo tipo
de alimentos, usam o mesmo tipo de armas e implementos que
estão em uso atualmente. Nós, por outro lado, em qualquer um
de nossos relatos históricos, lendas ou mitos, encontramos todo
um conjunto de condições culturais diferentes, que nos permitem
coordenar qualquer acontecimento com uma determinada época
e que nos faz perceber que um acontecimento histórico distante
- e, mais ainda, um acontecimento mitológico - ocorreu num
cenário de condições culturais inteiramente diversas daquelas em
que ora vivemos".
(MALINOWSKI, 1976, p. 231). (MALINOWSKI, 1976, p. 231).

Ora, mas se isso é assim, por que, então, se valer do argumento de Paul Pierson para analisar essas tribos que não reconhecem o curso sucessivo da história? $\mathrm{Ou}$, dito de outro modo, se essas sociedades não vivenciam a história como um desenrolar progressivo que produz um tipo de causa histórica que exige o enquadramento dos acontecimentos do presente aos ditames dos acontecimentos do passado, de que tipo é, então, a causa histórica que determina o curso temporal dessas sociedades? De fato, a aplicação pari passo do argumento de Pierson é inapropriada, mas sua utilização não é de todo descabida e nos exige apenas alguns ajustes.

$\mathrm{O}$ primeiro ajuste a ser feito baseia-se no argumento de Malinowski 
de que há uma diferença marcante, para esses nativos, entre aquilo que é histórico e o que está no âmbito do lendário. Isso, porque, apesar de possuírem os mesmos costumes, as personagens dos mitos viveram fatos que já não podem mais ser vivenciados e eram dotados de poderes que os nativos atuais, bem como seus ancestrais, não possuem mais. Sendo assim, valendo-se do argumento de Pierson, ao invés de conceberem o curso histórico como uma progressão de acontecimentos sucessivos, esses nativos a concebem como uma trajetória de degeneração. Além disso, essa degeneração não é progressiva, mas sim abrupta, pois o que impede os homens atuais de realizarem todas essas proezas descritas nos mitos consiste no esquecimento dos encantamentos que permitiam essas façanhas. Perder esse elo com o passado mítico representou a degeneração dos homens atuais, o que não pode ser refeito, pois não é possível recuperar o que já foi perdido, o que significa que há, para esses nativos, uma espécie de feedback negative que marca seu curso temporal, mas que não forma uma série progressiva de degeneração, e sim abrupta. Uma situação narrada por Malinowski revela bem essa diferença:

“Um professor-missionário, vindo das ilhas Fiji e sediado em Omarakana, estava falando sobre as máquinas voadoras do homem branco. Os nativos me perguntaram se o que ele dizia era verdade, e quando corroborei o relato do missionário de Fiji e lhes mostrei fotografias de aviões numa revista ilustrada perguntaramme se isso acontecia nos tempos atuais ou se era um lili' 'u'.

(MALINOWSKI, 1976, p. 231).

Há, então, uma diferença nítida entre a realidade histórica e a realidade mitológica para esses nativos, apesar de haver também uma íntima, vívida e verdadeira ligação entre ambas, o que nos leva à segunda ponderação a ser feita em relação ao argumento de Paul Pierson. Como já fora demonstrado a partir do relato de Malinowski, para esses nativos todo mito é rotulado como lili'u e sempre possui caráter sobrenatural. Mas é aí que advém o caráter mais interessante dessa relação, pois, apesar de distinguir os dois âmbitos, os nativos concebem um modo de acessar os poderes sobrenaturais das épocas míticas: os encantamentos mágicos. Ocorre que, por um lado, é verdade que os conhecimentos genuínos e completos dos encantamentos de outrora se perderam, o que impede que os homens se transformem em animais e as canoas voem. Mas, por outro lado, partes incompletas desses encantamentos foram legadas pelos ancestrais mitológicos aos homens 
atuais, o que lhes permite reproduzir, de maneira inacabada e imperfeita, as façanhas dos heróis mitológicos. É nisso que reside a importância da magia, pois ela permite a recuperação parcial do tempo mitológico, o que dá poderes sobrenaturais a quem conhece suas fórmulas.

Por isso, além de uma separação abrupta entre a época mitológica e a época histórica, o que caracteriza o processo histórico como um salto negativo e degenerativo, há também a noção de que esse passado mítico não fora perdido por completo e pode, por assim dizer, ser repetido por meio da magia. Sendo assim, a história para esses nativos, sobretudo no que se refere à sua vinculação com a realidade mitológica, não é apenas um processo abrupto e negativo, mas também parcialmente repetitivo, o que caracteriza seu curso histórico como um feedback repetitive. É em virtude dessa repetição dos mitos na realidade histórica, impetrada em função da magia que realiza a ponte entre ambos (mito e realidade), que a realidade histórica dessas sociedades vivencia também um tipo específico de causa histórica, que é, obviamente, distinta da causa histórica das sociedades ocidentais, apesar de essa diferença ser relativa, e não absoluta. É nesse ponto que as reflexões de Malinowski no Capítulo XVII devem ser explicitadas, pois é justamente nesse capítulo que o antropólogo aprofunda a análise do papel desempenhado pela magia na associação da realidade cotidiana ao âmbito mitológico, papel que permite a formação do feedback repetitive responsável pelas coagulações temporais que caracterizam a sociedade melanésia.

Antes de tudo, cumpre assinalar que a magia possui raízes muito sólidas na tradição, consistindo no item mais valioso e imutável do legado deixado pelas gerações anteriores. Além disso, ela também está assentada numa base sociológica, pois se trata de um legado deixado através do mecanismo da hereditariedade, o que justifica sua vinculação a determinados subclãs. Por fim, a magia é também algo essencialmente humano e representa a afirmação do poder intrínseco do homem sobre a natureza. Algo que, apesar de ter sido doado aos homens por um ser antropomórfico, está sob a posse dos homens e fora trazido por eles desde quando a humanidade saiu do subsolo para ocupar a superfície da terra. Logo, caso associemos essas definições de uma forma sintética, pode-se dizer que a magia representa, segundo a definição de Malinowski, a continuidade, mantida pela tradição, da época mitológica na época presente. Entretanto, a magia na atualidade, apesar de ser idêntica em natureza à magia que mobilizava forças sobrenaturais nos eventos míticos, possui, não obstante, poder e eficácia consideravelmente reduzida. Como afirma Malinowski: 
“Conforme já mostrei nesse capítulo, a magia nunca é considerada como uma invenção nova, mas é idêntica em natureza ao poder sobrenatural que constitui a atmosfera dos eventos míticos. Parte deste poder provavelmente se perdeu antes de chegar aos dias atuais; mas nunca se acrescentou nada a ele. Não há nada na magia de hoje que não tenha estado nela desde os tempos remotos e veneráveis do mito".

(MALINOWSKI, 1976, p. 298).

Em suma, portanto, Malinowski afirma que a magia, por representar o elo entre o mito e a realidade, possui, por um lado, o caráter supranormal das ocorrências míticas, mas está associado, por outro lado, a toda atividade humana praticada na atualidade, e é justamente por permitir essa associação entre o caráter sobrenatural dos mitos e a cotidianidade das atividades humanas que o mito pode permitir a formação daquele feedback repetitive que marca o curso histórico das sociedades melanésias. Ocorre que, como fora salientado, de um lado, o âmbito mitológico, definido pelos melanésios pelo termo lili'u, está apartado da realidade histórica atual de modo inexorável, o que impede os homens atuais de realizarem as mesmas proezas dos heróis míticos. Por outro lado, porém, a realidade mitológica não difere tanto assim da realidade atual, pois a terra e os homens foram e são sempre os mesmos, apesar de os homens atuais terem perdido a potência dos tempos mitológicos. Não obstante, aos homens atuais é reservada a possibilidade de acessar parcialmente essa potência perdida através dos encantamentos mágicos que lhes foram legados por seus ancestrais mitológicos. A associação dessa degeneração abrupta com a possibilidade de repetição ritual das origens é o que marca o curso histórico das sociedades melanésias:

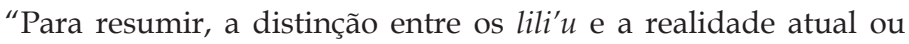
histórica é feita com firmeza e há, definitivamente, uma linha divisória entre as duas. Prima facie, esta distinção baseia-se no fato de que todo mito é rotulado como lili'u e conhecido por todos os nativos como tal. Outro sinal distintivo do mundo dos lili'u está no caráter sobrenatural, de certos acontecimentos neles incluídos. Os nativos acreditam que o sobrenatural é verdadeiro, e essa verdade é sancionada pela tradição e pelos diversos sinais e vestígios deixados pelas ocorrências míticas e, de maneira especial, pelos poderes mágicos transmitidos pelos ancestrais que viveram na época dos lili'u. Essa herança mágica é sem dúvida o elo mais palpável entre o presente e o passado mítico".

(MALINOWSKI, 1976, p. 232). 


\section{0 mito da canoa voadora de Kudayuri}

Para completar essa digressão, parece-nos pertinente apresentar um mito e sua relação com a cotidianidade das sociedades melanésias como exemplo demonstrativo dessa característica do curso histórico na melanésia. Escolhemos para tanto o mito da canoa voadora de Kudayuri, que constitui a base mitológica que dá sentido à série de rituais mágicos associados à construção da canoa utilizada nas expedições kula, estes que visam dar-lhe velocidade e estabilidade.

Kitava, distrito posicionado entre Wamwara e Tewara, é o centro da magia da canoa masawa, utilizada nas expedições kula, além de ser o distrito de ocorrência do mito da canoa voadora de Kudayuri, uma das aldeias de Kitava. Nesse mito, o protagonista principal é Mokatuboda, membro do clã Lukuba e nativo da aldeia de Kudayuri. Segundo o mito, ele, seu irmão mais novo, chamado Toweyre'i, e suas três irmãs - Kayguremwo, Na'ukuwakula e Murilmweyri'a - emergiram do solo em Labikewo, também um lugarejo presente no distrito de Kitava. Eles foram os primeiros possuidores $\left(u^{\prime} u l a\right)$ do encantamento ligogu e do encantamento wayugo, ambos associados à magia da canoa.

Certa vez, os nativos de Kitava decidiram fazer uma expedição kula à Koya e, por conta disso, iniciaram a montagem de suas canoas. Enquanto as aldeias do distrito de Kitava decidiram montar suas canoas na praia - o que era costumeiro, já que as canoas eram pesadas - os nativos da aldeia de Kudayuri decidiram montar sua canoa dentro da aldeia, em função da ordem de seu líder, Mokatudoba. Após todas as canoas estarem preparadas, Mokatudoba esperou que elas partissem em sua expedição e então realizou seu encantamento especial sobre sua própria canoa, o que a fizera voar. Assim ele pôde ultrapassar as outras canoas pelo ar, chegando antes delas em Koya, aldeia do distrito de Dobu. Quando as outras canoas desembarcaram, lá estava a canoa de Kudayuri, de onde saíra o cão Tokulubweydoga, animal mitológico que representa o clã Lukuba. Por conta dessa aparição inesperada, todos reconheceram Mokatuboda e se espantaram com o fato de que ele, apesar de ter partido posteriormente e de sua canoa estar ainda na aldeia quando partiram, chegara primeiro em Dobu. Onde teria passado? Como chegaram tão rápido? Sem respostas, os nativos resolveram partir para Vakuta e depois para Gumasila e novamente a canoa de Kudayuri chegou primeiro, o que deixou os nativos de Kitava perplexos. 
Isso se repetiu por toda a expedição, até que seus companheiros perceberam o motivo do sucesso da canoa de Mokatuboda, já que sua canoa podia voar, e se zangaram com isso. Não obstante, Mokatuboda também dominava a magia maligna do clima, o que lhe permitira trazer chuva apenas para a sua roça, prejudicando seus companheiros. E foi justamente após ter aplicado essa magia climática que os outros nativos se cansaram de sua supremacia e decidiram planejar uma vingança contra Mokatuboda: desejavam assassiná-lo. Entretanto, apesar de todos os nativos de todas as aldeias de Kitava estarem sedentos por vingança, foram justamente os irmãos e os sobrinhos maternos de Mokatuboda que o assassinaram. Com isso, apesar de serem os herdeiros legítimos de seus conhecimentos mágicos - o que permitira a Mokatuboda fazer sua canoa voar e trazer a chuva para a sua roça - seus irmãos e sobrinhos não puderam obter os encantamentos especiais.

Como acreditavam que, por dominarem os conhecimentos de Mokatuboda, também poderiam fazer sua canoa voar, na expedição seguinte, seu irmão mais novo, chamado Toweyre'i, decidiu construir a canoa dentro da aldeia, e não na praia, com a esperança de que conseguiria fazê-la voar assim como seu irmão assassinado conseguira. Os mesmos processos se repetiram até que Toweyre'i entrou em sua canoa e se preparou para voar. O problema é que Toweyre'i não conhecia devidamente o encantamento que permitira Mokatuboda fazer sua canoa voar e, portanto, não obteve sucesso. Sua canoa não voou e, ao contrário de todas as outras aldeias de Kitava, a aldeia de Kudayuri não pôde realizar o Kula.

Sobre o mito cumpre assinalar, antes de tudo, que as condições das personagens narradas no mito não diferem em nada das condições dos nativos na atualidade. Todos eles respeitam as mesmas regras de parentesco quanto à herança dos conhecimentos mágicos e das posições de liderança; todos se preocupam na mesma medida com a realização das expedições kula; todos precisam realizar os mesmos encantamentos e adotarem as mesmas técnicas nas construções das canoas utilizadas na expedição. No entanto, o conhecimento mágico possuído por Mokatudoba lhe permitira fazer com que sua canoa voasse, o que somente ele era capaz de realizar. Esse legado teria sido passado para seus descendentes diretos, já que eles eram seus herdeiros legitimamente reconhecidos pela tradição, mas eles o assassinaram antes que Mokatudoba o fizesse. Como somente ele os conhecia, o que era já um legado de seus antepassados, esse encantamento se perdeu no tempo e, por isso, as canoas de Kudayuri, apesar de possuírem 
uma velocidade extra em comparação com as demais, hoje não voam mais.

Assim se revela que as proezas narradas no mito, primeiramente, não podem ser repetidas perfeitamente nos tempos atuais, em virtude do equívoco do irmão mais novo de Mokatudoba, que o assassinara sem obter o encantamento original que permitira fazer sua canoa voar. Contudo, por outro lado, ele também mantém uma íntima relação com a realidade atual, pois, ainda que de modo imperfeito, os nativos de Kudayuri ainda conseguem imprimir velocidade extra às suas canoas em virtude de seus conhecimentos incompletos do encantamento de Mokatudoba:

\begin{abstract}
"O conto de Kudayuri, por um lado, descreve minunciosamente as condições sociológicas dos heróis, suas ocupações e preocupações - que não diferem em nada das atuais. Por outro lado, nos mostra o herói dotado de poderes verdadeiramente sobre-humanos, através de sua magia da construção da canoa e da magia da chuva. Nem seria possível afirmar, de maneira mais convincente do que se afirma nessa narrativa, que o conhecimento completo da magia apropriada era o único fator responsável por esses poderes sobrenaturais".
\end{abstract}

(MALINOWSKI, 1976, p. 241).

Malinowski destaca também que, apesar de ter causado inveja em todos os nativos de seu distrito, foram justamente seus parentes consanguíneos - irmãos e sobrinhos - que o assassinaram, certamente em virtude do fato de almejarem assumir sua posição de liderança. Por isso, seu irmão mais novo, que assumira sua função de liderança, só se lamentaria pela morte do irmão ao perceber que fora ludibriado por ele e que, portanto, não possuía a magia que lhe permitiria fazer sua canoa voar. É justamente esse equívoco de Toweyre'i que justifica a imperfeição dos encantamentos atuais, pois já não é mais possível reproduzir o sucesso de Mokatudoba, uma vez que seu encantamento especial se perdeu definitivamente após sua morte. Logo, por um lado, é possível repetir de forma incompleta as proezas de outrora, através dos encantamentos mágicos que perduraram com o passar do tempo (feedback repetitive). No entanto, por conta desse assassinato e da perda que ele representa, as épocas atuais não são capazes de reproduzir as proezas da mitológica canoa de Kudayuri, o que justifica a degeneração dos tempos atuais em relação ao tempo mitológico, em virtude de um acontecimento que separa a ambos através de um abismo (feedback negative): 
"No mito da canoa, por exemplo, o vôo, conquista supranormal da canoa de Kudayuri, é concebido apenas como o mais alto grau do poder da velocidade que ainda hoje vem sendo infundido nas canoas pela magia. O legado mágico do clã Kudayuri existe até hoje, fazendo com que as canoas naveguem velozmente. Se tivesse sido transmito em sua totalidade, qualquer canoa de hoje, como a canoa mítica, poderia voar".

(MALINOWSKI, 1976, p. 249).

\section{Conclusão}

Ao longo deste artigo nos ocupamos em demonstrar as peculiaridades da trajetória histórica melanésia. Sua experiência histórica não é marcada por um processo de formação de trajetórias lineares que apresentam um grau elevado de irreversibilidade. Pelo contrário. Sua experiência histórica é circular e está baseada numa contínua associação entre o mito e a realidade, o que concede a marca própria de sua experiência, que não é progressiva e linear, mas sim degenerativa, abrupta e circular. Deve estar claro, contudo, que as conclusões tiradas deste artigo não devem servir apenas à compreensão dessas sociedades arcaicas, mas também para que possamos compreender com mais profundidade o que as distingue das sociedades modernas. Isso porque compartilhamos com Dumont a convicção expressa em seu Homo aequalis (DUMONT, 2000) de que a sociedade moderna é uma derivação das sociedades tradicionais, o que significa que seu modo próprio de vivenciar o fluxo histórico está alicerçado por uma ruptura estabelecida pelos modernos em relação às sociedades tradicionais e arcaicas. Mas essa deve ser apenas uma indicação, pois essa reflexão supera já o intento deste artigo.

\section{Referências}

DUMONT, Louis.

(2000) Homo Aequalis: gênese e plenitude da ideologia econômica. Bauru / SP, EDUSP.

GEERTZ, Clifford.

(2007). 0 Saber Local. Petrópolis / RJ, Editora Vozes.

(1989). A Interpretação das Culturas. Rio de Janeiro, LTC Editora.
HABERMAS, Jürgen.

(1987). Teoria de la Accion Comunicativa. Madrid, Taurus.

HALL, Peter.; TAYLOR, Rosemary.

(2003). As Três Versões do NeoInstitucionalismo. Lua Nova. n. 58.

LÉVI-STRAUSS, Claude.

(1982) As Estruturas Elementares do Parentesco. Petrópolis / RJ: Editora Vozes. 
MARCH, James; Olsen, Johan.

(1989). Rediscovering Institutions: The Organizational Basis of Politics. New York, The Free Press.

NORTH, Douglas.

(1990). Institutions, Institutional Change and Economics Performance. Cambridge, Cambridge University Press.

PIERSON, Paul. (2004). Politics in time: History, Institutions, and Social Analysis. New Jersey, Princeton University Press.

SIMMEL, Georg.

(2011). Ensaios sobre Teoria da História. Rio de Janeiro, Contraponto.
(1890). Über sociale Differenzierung. Leipzig, Verlag von Duncker \& Humblot.

THERET, Bruno.

(2003). As instituições entre as estruturas e as ações. Lua Nova, n. 58.

\section{Recebido em}

abril de 2015

Aprovado em março de 2017 